\title{
KINETIKA PENGERINGAN LAPIS TIPIS PUREE LABU KUNING (Cucurbita moschata)
}

\author{
Indah Hartati*, Salsa Erna Setiawati, Suwardiyono \\ Jurusan Teknik Kimia Fakultas Teknik Universitas Wahid Hasyim \\ *Email: hartatiprasetyo@gmail.com
}

\begin{abstract}
Abstrak
Pengolahan daging buah labu kuning menjadi tepung melalui proses pengeringan dapat meningkatkan umur simpan produk, mempermudah penggunaan dan pengolahannya menjadi berbagai produk lanjutan, mempermudah proses penyimpanan serta dapat digunakan untuk berbagai keperluan. Penelitian ini bertujuan untuk mengkaji pengaruh suhu pada proses pengeringan daging buah labu kuning serta memvalidasi model kinetika lapis tipis Lewis, Henderson Pabis, Page, Midili dan Two Term menggunakan data eksperimen pengeringan daging buah labu kuning. Proses pengeringan dilakukan menggunakan pengering tipe rak

pada suhu $60-70^{\circ} \mathrm{C}$. Hasil penelitian menunjukkan jika proses pengeringan pada suhu $70^{\circ} \mathrm{C}$ selama 165 menit merupakan kondisi proses pengeringan yang dianggap relatif baik karena mampu menghasilkan produk dengan nilai moisture ratio yang rendah yakni 0,04. Berdasarkan nilai RSS-nya, model kinetika pengeringan Midili merupakan model kinetika pengeringan lapis tipis yang memiliki kesesuaian tertinggi dengan data eksperimen proses pengeringan puree labu dibandingkan model kinetika lapis tipis Lewis, Henderson Pabis, Page, dan Two Term. Nilai konstanta kinetika pengeringan puree labu kuning adalah 9.10-8
\end{abstract}

$2,4.10^{-7} 1 /$ menit untuk proses pada suhu $60-70^{\circ} \mathrm{C}$.

Kata kunci: labu kuning, model kinetika, Midili, lapis tipis

\section{PENDAHULUAN}

Labu kuning (Cucurbita moschata) merupakan salah satu bahan pangan yang kaya akan senyawa bioaktif seperti karotenoid, asam phenolat, flavonol, mineral dan vitamin (Kulczynski and Gramza-Michałowska, 2019; Sandhya and Sisodia, 2019). Zeaxanthin, lutein, beta-carotene dan retinol adalah jenis jenis karotenoid yang terdapat pada buah labu. Labu kuning dinyatakan mengandung berbagai jenis asam fenolat seperti asam gallat, asam vanilat, asam cafeat, asam ferulat dan asam sinapinat (Kulczynski and Gramza-Michałowska, 2019). Berbagai senyawa bioaktif yang terkandung pada labu kuning tersebut dinyatakan memiliki berbagai pengaruh positif terhadap kesehatan manusia (Kulczynski and GramzaMichałowska, 2019).

Karotenoid pada labu kuning dinyatakan memiliki aktifitas antioksidan yang tinggi (Abbas et al., 2020) sementara senyawa phenolic pada labu disebutkan memiliki aktifitas anti diabetes dilihat dari kemampuannya menghambat $\beta$-glucosidase dan $\alpha$-amylase (Sandhya and Sisodia, 2019). Selain mengandung berbagai senyawa bioaktif, labu kuning juga dinyatakan sebagai sumber serat pangan. Total serat pangan pada tepung labu kuning dinyatakan mencapai 14,81-35,32\% (Nurjanah, Setiawan and Roosita, 2020).
Kandungan serat pangan pada labu kuning dinyatakan mampu menurunkan tingkat kolesterol, resiko penyakit jantung coroner dan hipertensi (Mendelová et al., 2017).

Kulit buah labu kuning yang tebal menjadikannya sebagai salah satu produk yang memiliki daya simpan yang lama. Namun demikian menimbang berbagai manfaat positif dari komponen-komponen buah labu kuning, pengolahan lebih lanjut daging buah labu kuning menjadi berbagai produk turunan dari labu kuning perlu untuk diupayakan. Salah satu alternative produk setengah jadi dari labu kuning adalah dengan mengolahnya menjadi tepung melalui proses penggilingan dan pengeringan. Pengeringan merupakan salah satu teknik yang paling banyak diaplikasikan pada pengawetan produk pangan (Onwude et al., 2016).

Model kinetika proses pengeringan mampu memberikan gambaran terkait laju perubahan fisik maupun kimia dari produk secara kuantitatif, dapat memberikan pemahaman yang lebih baik terhadap mekansime proses serta memberikan data data dasar yang dapat digunakan pada proses perancangan alat proses dalam skala yang lebih besar. Oleh karenanya dalam penelitian ini telah dilakukan proses pengeringan puree labu kuning pada berbagai suhu dan data pengeringan yang diperoleh 
digunakan untuk memvalidasi beberapa model kinetika pengeringan lapis tipis yang terdiri dari model Lewis, Page Henderson dan Pabis, Midili dkk, dan Two term.

\section{METODOLOGI}

\subsection{Bahan}

Bahan yang digunakan dalam penelitian ini adalah labu kuning yang diperoleh dari daerah Bandungan Kabupaten Semarang. Kulit buah labu kuning dihilangkan dengan pengupasan. Daging buah labu kuning dipisahkan dari bijinya serta dipotong menggunakan chopper. Potongan daging buah labu kuning dihaluskan menggunakan blender sehingga menjadi puree dan digunakan sebagai bahan baku pada proses pengeringan labu kuning.

\subsection{Proses pengeringan}

Sebanyak 50 gram puree labu kuning diletakkan didalam loyang dengan ketebalan $0.2 \mathrm{~cm}$ dan letakkan di dalam rak teratas pada pengering tipe rak. Proses pengeringan dilakukan pada suhu $60-70^{\circ} \mathrm{C}$ dan proses pencatatan penurunan berat sampel dilakukan pada interval waktu 10 menit. Kandungan air dari sampel segar dan kering ditentukan menggunakan metode AOAC (1995). Laju pengeringan ditentukan berdasarkan berat air yang dipisahkan persatuan waktu dan pergram berat sampel (basis kering) serta dinyatakan dalam satuan $\mathrm{g} / \mathrm{g}^{-1} /$ menit.

\subsection{Analisa Data}

Data kadar air digunakan untuk menentukan nilai moisture ratio menurut persamaan 1.

$$
M R=\frac{M_{t}}{M_{0}}
$$

dimana $M_{0}$ adalah kadar air awal dan $M_{t}$ adalah kadar air pada $t$ tertentu.

\subsection{Model kinetika lapis tipis}

Model kinetika pengeringan yang digunakan untuk menganalisa kinetika pengeringan disajikan pada Tabel 1 dan nilai RSS ditentukan menurut persamaan 2.

$$
R S S=\left(M R_{p r e, i}^{i}-M R_{e k s, i}\right)^{2}[2
$$

Tabel 1. Model kinetika pengeringan

\begin{tabular}{lll}
\hline \multicolumn{1}{c}{$\begin{array}{c}\text { Model } \\
\text { Kinetika }\end{array}$} & \multicolumn{1}{c}{ Persamaan Model Kinetika } & Referensi \\
\hline Lewis & $M R=\exp (-k t)$ & \\
Page & $M R=\exp \left(-k t^{n}\right)$ & (Inyang, \\
& Oboh and \\
Henderson & $M R=a \exp (-k t)$ & Etuk, 2018) \\
Pabis & & \\
Midili & $M R=a \exp (-k t)+b t$ & \\
Two term & $M R=a \exp \left(-k_{0} t\right)+b \exp \left(-k_{1} t\right)$ & \\
& & \\
\hline
\end{tabular}

\section{HASIL DAN PEMBAHASAN}

Proses pengeringan daging buah labu kuning dilakukan pada 3 suhu yang berbeda yakni $60^{\circ} \mathrm{C}, 65^{\circ} \mathrm{C}$ dan $70^{\circ} \mathrm{C}$. Suhu proses ditentukan mulai dari $60^{\circ} \mathrm{C}$ merujuk suhu yang diaplikasikan pada pengeringan puree labu (Dutta et al., 2006). Pengaruh temperature pada proses pengeringan labu kuning terhadap kinetika degradasi beta carotene pada puree labu telah dikaji dengan menerapkan suhu proses pengeringan $60-100^{\circ} \mathrm{C}$ (Dutta et al., 2006). Mereka menyatakan bahwa diatas suhu $60^{\circ} \mathrm{C}$, beta carotene terdegradasi thermal sebagai akibat dari proses oksidasi dan non oksidasi seperti proses isomerisasi cis-trans dan pembentukan epoksida.

Suhu proses pengeringan tertinggi yang dikaji dalam penelitian ini adalah $70^{\circ} \mathrm{C}$. Hal tersebut didasarkan bahwa pada suhu diatas $70^{\circ} \mathrm{C}$, bila dibandingkan nilai beta carotene pada suhu $60^{\circ} \mathrm{C}$ lebih dari $42 \%$ beta carotene terdegradasi thermal (Dutta et al., 2006). Nilai moisture ratio serta laju pengeringan dari proses pengeringan labu kuning yang dikeringkan pada suhu $60-70^{\circ} \mathrm{C}$ disajikan pada Gambar 1.

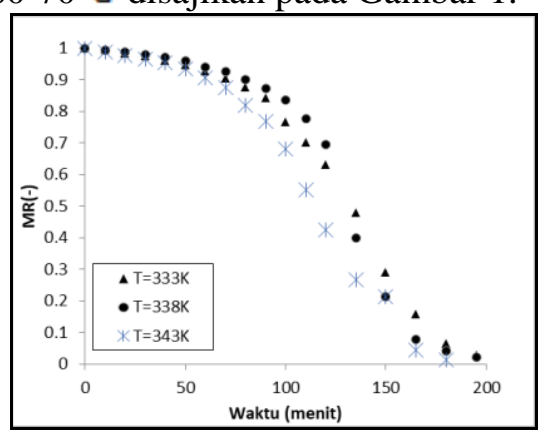

(a) 


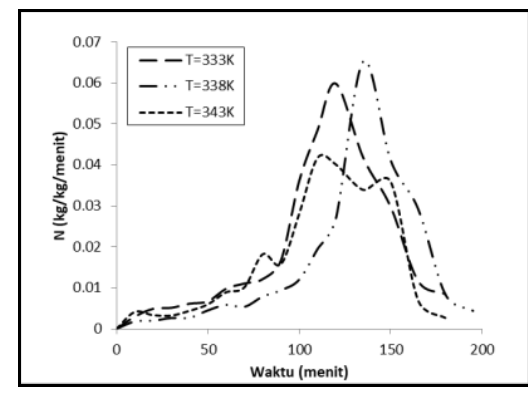

(b)

Gambar 1. Moisture Ratio (MR) dan laju pengeringan dari proses pengeringan labu kuning yang dikeringkan

$$
\text { pada suhu } 60-70^{\circ} \mathrm{C}
$$

Gambar 1a dan 1b menunjukkan bahwa pada waktu $t=0$ menit hingga $=50$ menit, peningkatan suhu proses pengeringan tidak memberikan pengaruh terhadap penurunan nilai moisture content (MR) puree labu kuning ataupun terhadap laju pengeringan. Penurunan MR pada proses pengeringan pada $t=0$ menit hingga $=50$ menit cenderung asimtotis. Pengaruh suhu proses pengeringan mulai terlihat pada durasi proses pengeringan 50 menit keatas dimana penurunan tajam moisture content mulai terlihat untuk ketiga suhu yang diterapkan.

Gambar 1a menunjukkan jika proses pengeringan pada suhu $70^{\circ} \mathrm{C}$, penurunan nilai moisture ratio produk puree labu kuning dapat dicapai pada waktu yang lebih singkat bila dibandingkan proses pada suhu 60 dan $65^{\circ} \mathrm{C}$. Nilai moisture ratio sebesar 0,15 dan 0,07 diperoleh dari proses pengeringan pada suhu 60 dan $65^{\circ} \mathrm{C}$ selama 165 menit. Sementara proses pengeringan pada suhu $70^{\circ} \mathrm{C}$ selama 165 menit mampu memberikan produk serbuk labu kuning dengan nilai moisture ratio sebesar 0,04. Hal tersebut menunjukkan bahwa semakin tinggi suhu yang diterapkan pada proses pengeringan, semakin besar air yang dapat dipisahkan dari matriks bahan. Proses pengeringan pada suhu $70^{\circ} \mathrm{C}$ selama 165 menit dapat dipandang sebagai kondisi prose yang relatif baik bagi proses pengeringan puree labu kuning.
Beberapa peneliti juga telah mengkaji proses pengeringan puree labu kuning dimana satu diantaranya adalah proses pengeringan menggunakan metode pengeringan beku (Caliskan and Dirim, 2014). Proses pengeringan beku tersebut dilakukan dengan mengeringkan puree labu kuning dengan ketebalan lapisan sebesar $3 \mathrm{~mm}$ dan dikeringkan pada kondisi vakum (13.33 Pa), dengan suhu kondensor - 48 ${ }^{\circ} \mathrm{C}$ serta suhu plate sebesar $30^{\circ} \mathrm{C}$. Proses tersebut membutuhkan waktu hingga 8 jam untuk menghasilkan serbuk labu kuning dengan nilai moisture ratio dibawah 0,1 (Caliskan and Dirim, 2014).

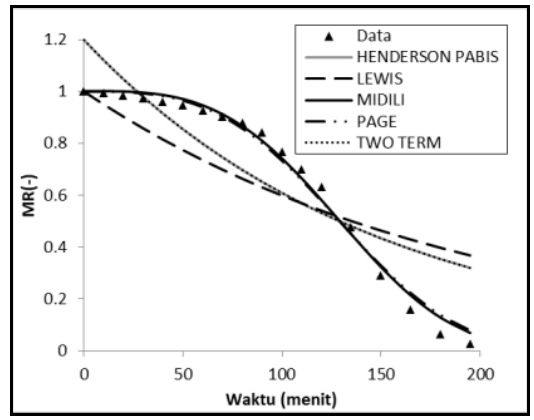

(a)

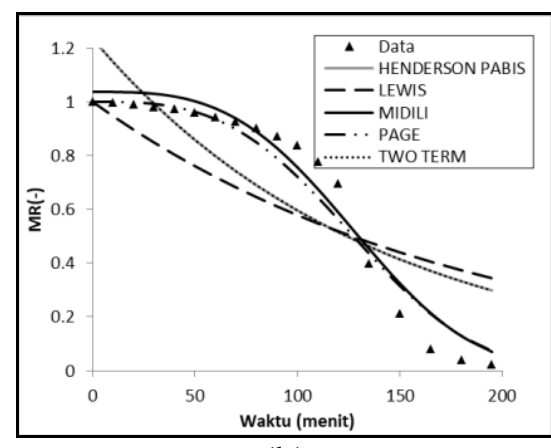

(b)

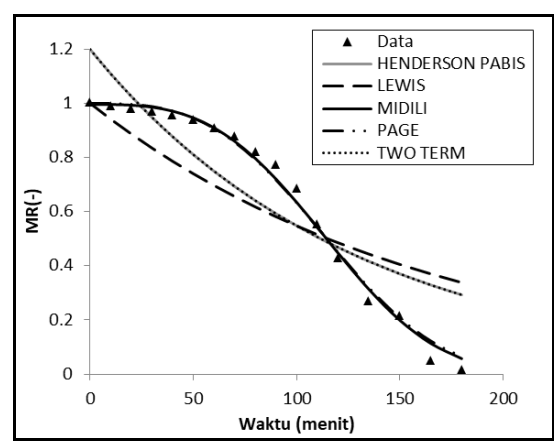

(c)

Gambar 2. Nilai MR yang diperoleh dari proses

eksperimen pada suhu (a) $60^{\circ} \mathrm{C}$, (b) $65^{\circ} \mathrm{C}$ dan (c) $70^{\circ} \mathrm{C}$; serta komparasinya dengan nilai MR yang diperoleh dari model kinetika lapis tipis tipis Lewis, Page Henderson dan Pabis, Midili dkk, dan Two term 
Lebih lanjut data yang diperoleh dari proses pengeringan puree labu kuning pada suhu 60-

$70^{\circ} \mathrm{C}$ digunakan untuk memvalidasi model kinetika pengeringan lapis tipis Lewis, Page Henderson dan Pabis, Midili dkk, dan Two term (Gambar 2). Hasil penelitian menunjukkan jika dilihat dari nilai RSS-nya (Tabel 1), model kinetika lapis tipis Midili menunjukkan tingkat kesesuaian yang paling tinggi bila dibandingkan dengan model kinetika lapis tipis lain yang dikaji dalam penelitian ini. Nilai RSS untuk model kinetika lapis tipis Midili adalah sebesar 0,01947-0,01605 untuk proses pengeringan puree labu kuning pada suhu $60-70^{\circ} \mathrm{C}$.

Hasil penelitian serupa ditunjukkan dari kajian kinetika pengeringan lapis tipis puree buah labu menggunakan metode pengeringan beku (Caliskan and Dirim, 2014). Model Midili termodifikasi memberikan nilai RMSE yang paling kecil yakni sebesar 0,02; dibandingkan nilai RMSE model Page sebesar 0,034; Two Term sebesar 0,048; Henderson Pabis sebesar 0,048 dan Lewis sebesar 0,050 (Caliskan and Dirim, 2014). Jika dilihat dari data nilai RSS pada penelitian ini dan nilai RMSE pada penelitian yang dilakukan oleh Caliskan dan Dirim. (2014), maka urutan kesuaian model berdasarkan dari yang paling sesuai adalah Midili-Modified Midili, Page, Two Term, Henderson-Pabis serta Lewis.

Tabel 1. Parameter model kinetika pengeringan

\begin{tabular}{|c|c|c|c|c|c|c|c|}
\hline \multirow{2}{*}{$\begin{array}{c}\text { Model } \\
\text { Kinetika } \\
\text { Pengeringan }\end{array}$} & \multirow{2}{*}{ Suhu } & \multicolumn{5}{|c|}{ Parameter Model Kinetika Pengeringan } & \multirow{2}{*}{ RSS } \\
\hline & & $\mathrm{k}_{1}$ & $\mathrm{~N}$ & $\mathrm{a}$ & B & $\mathrm{k}_{2}$ & \\
\hline \multirow{3}{*}{ Lewis } & $333 \mathrm{~K}$ & 0,00512096 & & & & & 0,625 \\
\hline & $338 \mathrm{~K}$ & 0,00546968 & & & & & 0,961 \\
\hline & $343 \mathrm{~K}$ & 0,00601939 & & & & & 0,563 \\
\hline \multirow{3}{*}{ Page } & $333 \mathrm{~K}$ & 0,00000016 & 3,14 & & & & 0,024 \\
\hline & $338 \mathrm{~K}$ & 0,00000019 & 3,11 & & & & 0,100 \\
\hline & $343 \mathrm{~K}$ & 0,00000038 & 3,04 & & & & 0,019 \\
\hline \multirow{3}{*}{ Midili } & $333 \mathrm{~K}$ & 0,00000009 & 3,26 & 1,002 & 0,00000100 & & 0,019 \\
\hline & $338 \mathrm{~K}$ & 0,00000012 & 3,21 & 1,036 & 0,00000100 & & 0,088 \\
\hline & $343 \mathrm{~K}$ & 0,00000024 & 3,14 & 0,996 & 0,00000100 & & 0,016 \\
\hline \multirow{3}{*}{$\begin{array}{c}\text { Henderson } \\
\text { Pabis }\end{array}$} & $333 \mathrm{~K}$ & 0,00676953 & & 1,198 & & & 0,476 \\
\hline & $338 \mathrm{~K}$ & 0,00728410 & & 1,234 & & & 0,748 \\
\hline & $343 \mathrm{~K}$ & 0,00782731 & & 1,199 & & & 0,426 \\
\hline \multirow{3}{*}{ Two term } & $333 \mathrm{~K}$ & 0,00676653 & & 0,002 & 1,19642245 & 0,0067 & 0,476 \\
\hline & $338 \mathrm{~K}$ & 0,00728442 & & 1,235 & 0,00000100 & 0,0002 & 0,748 \\
\hline & $343 \mathrm{~K}$ & 0,00782645 & & 1,199 & 0,00000100 & 3,1407 & 0,426 \\
\hline
\end{tabular}

Validasi model kinetika pengeringan lapis tipis menghasilkan konstanta kontanta parameter model kinetika pengeringan lapis tipis puree labu kuning (Tabel 1). Tabel 1 menunjukkan bahwa untuk semua model, pada suhu yang semakin tinggi, nilai konstanta kinetika pengeringan yang diperoleh adalah semakin besar. Nilai konstanta kinetika pengeringan puree labu kuning berdasar model kinetika pengeringan lapis tipis Midili diperoleh sebesar $9 \times 10^{-8}-2,4 \times 10^{-7} 1 /$ menit untuk proses pengeringan pada suhu $60-70^{\circ} \mathrm{C}$. Nilai konstanta kinetika pengeringan untuk model yang lain, sebagai contoh, dari model Henderson Pabis, diketahui bahwa nilainya berkisar antara $6,7 \times 10^{-3}-7,8 \times 10^{-3}$. Kontanta kinetika pengeringan yang diperoleh dari penelitian ini lebih 100 kali lebih besar bila dibandingkan dengan konstanta kinetika pengeringan puree labu kuning yang dikeringkan menggunakan pengeringan beku serta dimodelkan menggunakan model

Henderson Pabis, yakni sebesar 9,36 $\times 10^{-5}$ (Caliskan and Dirim, 2014). Hal ini menunjukkan jika dilihat dari kecepatan pengeringan, maka pengeringan menggunakan pengering tipe rak dengan pemanasan konvensional jauh lebih cepat bila dibandingkan proses pengeringan beku. Namun demikian dapat jadi pengeringan konvensional memiliki dampak negatif terhadap produk seperti terjadi degradasi termal komponen komponen bioaktif yang terdapat pada buah labu kuning.

\section{KESIMPULAN}

Dari hasil penelitian ini dapat disimpulkan bahwa:

1) Suhu proses pengeringan berpengaruh terhadap moisture rasio dari produk

2) Pengeringan pada suhu $70^{\circ} \mathrm{C}$ selama 165 menit dapat dianggap sebagai kondisi proses pengeringan yang relatif baik karena mampu menghasilkan produk dengan nilai moisture ratio yang rendah yakni 0,04 .

3) Model kinetika pengeringan Midili merupakan model kinetika pengeringan lapis tipis yang memiliki kesesuaian tertinggi dengan data eksperimen proses pengeringan puree labu dibandingkan model kinetika lapis tipis Lewis, Henderson Pabis, Page, dan Two Term.

4) Penelitian ini menghasilkan data data konstanta kinetika pengeringan yang dapat digunakan sebagai dasar dasar untuk perancangan alat proses pengering tipe rak 


\section{DAFTAR PUSTAKA}

Abbas, H. M. K., Xue, D., Yan, J., Wu, Q., Huang, W. (2020). Evaluation of Metabolites and Antioxidant Activity in Pumpkin Species. 15(4), Natural Product Communications. Volume 15. No (4). Hal: $1-11$.

Caliskan, G. and Dirim, S. N. (2014).Determination Of The Freeze Drying Kinetics Of Pumpkin ( Cucurbita Moschata ) Puree ( Cucurbita Moschata) Puree. 19th International Drying Symposium (IDS 2014).

Dutta, D. Dutta, A., Raychaudhuri, U., Chakraborty, R. (2006). Rheological characteristics and thermal degradation kinetics of beta-carotene in pumpkin puree. Journal of Food Engineering. Volume 76. Hal:538-546.

Inyang, U. E., Oboh, I. O. and Etuk, B. R. (2018). Kinetic Models for Drying Techniques - Food Materials. Advances in Chemical Engineering and Science. Volume 2018. No 8. Hal: 27-48.

Kulczynski, B. and Gramza-Michałowska, A. (2019). The Profile of Secondary Metabolites and Other Bioactive Compounds in Cucurbita pepo L. and Cucurbita moschata Pumpkin Cultivars. Molecules. Volume 24. No 2945. Hal: 122.

Mendelová, A. et al. (2017). Winter squash (Cucurbita Moschata Duch) fruit as a source of biologically active components after its thermal treatment. Potravinarstvo Slovak Journal of Food Sciences. Volume 11. No. 1. Hal: 489-495.

Nurjanah, H., Setiawan, B. and Roosita, K. (2020). Potensi Labu Kuning (Cucurbita moschata) sebagai Makanan Tinggi Serat dalam Bentuk Cair. Indonesian Journal of Human Nutrition. Volume 7. No. 1. Hal: $54-68$

Onwude, D. I. et al. (2016). Modeling the ThinLayer Drying of Fruits and Vegetables : A Review. Comprehensive Reviews in Food Science and Food Safety 15.

Sisodia, S. S. (2019). Phytochemical and Pharmacological Aspects of Cucurbita moschata and Moringa oleifera. UK Journal of Pharmaceutical and Biosciences. Volume 6. No 6. Hal: 45-53 